\title{
A NEWLY RECORDED CRAB-SPIDER GENUS Misumenoides F.O. PICKARD-CAMBRIDGE, 1900 (ARANEAE: THOMISIDAE) FROM KHULNA, BANGLADESH
}

\author{
Biswas, V. \\ Department of Zoology, Khulna Govt. Womens' College, Khulna-9000, Bangladesh
}

\begin{abstract}
A study on the crab-spider genus Misumenoides F. O. Pickard-Cambridge, 1900 (Araneae: Thomisidae) was carried out in Khulna, Bangladesh. One species namely - M. deccanes Tikader was recorded for the first time from the present study area. Illustrated description and distribution of the species are provided together with generic diagnosis.
\end{abstract}

Key words: Crab-spiders; New record; Misumenoides; Araneae; Thomisidae; Bangladesh.

\section{INTRODUCTION}

Spiders of the family Thomisidae (crab spiders) are common members in the gardens and forests. They are very attractive and beautiful and usually found on the leaves and petals of colourful flowers in the gardens. These spiders are distributed all over the world and at present, have over 2,155 species under 175 genera in the world fauna (World Spider Catalog 2019). Members of the genus Misumenoides are typical in shape and very slow in movement. They do not spin any web in their habitat but sometimes make specialized nests during breeding season.

The genus was first erected by F.O. Pickard-Cambridge in 1900 with the type-species M. magnus (Keyserling 1880) and till date, 36 species are described worldwide (World Spider Catalog 2019). But there is no description of this spider in this region of Bangladesh (Chowdhury and Nagari 1981, Okuma et al. 1993, Biswas 1995, Biswas and Raychaudhury 2016) although a good number of works are available on this genus in other Asaian countries like- India (Tikader, 1980, 1987, Majumder 2005, Keswani et al. 2012), China (Chen and Zhang 1991, Song and Zhu 1997, Song et al. 1999), Japan (Yaginuma 1986, Ono 1988), Philippines (Barrion and Litsinger 1995) and Korea (Paik 1978, Namkung 2003).

The present paper deals with an illustrated description of a newly recorded species $M$. deccanes Tikader from Khulna, Bangladesh together with the distribution and generic diagnosis.

\section{Collection and Preservation}

\section{MATERIAL AND METHODS}

Spiders of the genus Misumenoides are sluggish in habit and stay on the leaves or petals of coloured flowers, spreading legs. They can show a remarkable degree of mimicry; and that is why, sometimes they are very difficult to identify their occurrence in the garden. Specimens were collected by handpicking and by jerking the branches of trees on the inverted umbrella placed underneath the bushes and trees (Tikader 1987). The collected specimens were anesthetized with chloroform in a killing jar in the field and were then transferred to a Petridis filled with $70 \%$ ethanol for sorting.

After sorting, the specimens were kept 3-4 hours in another larger petridish with 70\% ethanol for relaxing and loosing its body muscles. The ready specimens were then preserved temporarily in separate vials filled with $70 \%$ ethanol for identification. After identification, the specimens were preserved permanently in 'Audmans Preservatives' ( 85 parts $70 \%$ alcohol +5 parts glycerine +5 parts glacial acetic acid) (Lincoln and Sheals 1985). 


\section{Identification}

Spiders thus preserved, were identified following - Pocock (1900), Schick (1965), Dondale and Redner (1978), Tikader (1980, 1987), Yaginuma (1986), Ono (1988), Chen and Zhang (1991), Barrion and Litsinger (1995), Song and Zhu (1997), Song et al. (1999), Majumder (2005), Biswas (2009), Kim and Lee (2012) and Sen et al. (2015). The identity of the species was later confirmed from the Zoological Survey of India, Kolkata.

Figures were drawn using camera Lucida fitted with Stereo Binocular Microscope (SV8, Zeiss). All the measurements were taken in millimeters $(\mathrm{mm})$ under microscopic observation. Leg measurements are shown as: total length of different parts (viz. femur, patella, tibia, metatarsus and tarsus).

\section{Taxonomy}

\section{RESULTS AND DISCUSSION}

Family: THOMISIDAE Sundevall, 1833

Genus: Misumenoides F.O. Pickard-Cambridge, 1900

Type-species: M. magna (Keyserling) 1900.

Misumenoides F.O. Pickard-Cambridge, Biol. Centr. Amer. Zool., 2: 136. Gertsch, 1939: 309; MelloLeitao, 1941: 163; Chamberlin \& Ivie, 1944; 157; Caporiacco, 1955: 412; Tikader, 1963: 258; Schick, 1965: 105; Dondale \& Redner, 1978: 129; Tikader 1980; 150; Jimenez, 1992: 53; Barrion \& Litsinger, 1995: 241; Platnick, 1997: 830; Mikhailov, 1997: 194; Gajbe, 2004: 104; Biswas \& Roy, 2008: 48; Biswas, 2009: 348; Teixeira \& Lise, 2012: 381. [All synonyms and references are listed in the World Spider Catalog (2019)]

\section{Diagnosis}

Spiders of the genus Misumenoides F.O. Pickard-Cambridge are small to medium in size. Cephalothorax is relatively flat, clypeus vertical with a white anterior carina curving to allutum. Lateral eyes situated on a common and strongly projecting process. Tibia I and II without prolateral spiniforms and without a ventrolateral spiniform ; tarsi I and II without prolateral spiniforms.

Abdomen nearly flat, enlarged posterolaterally, with variously decorated dorsum; ventrally pale in colour; epigynum and spinnerets are typical in different species.

\section{Biological note}

These spiders are small to medium in size and brownish in colour. Cephalothorax brown and legs green. They are commonly found in the garden, on the leaves and bright coloured flowers. They cannot spin any web but can make typical nests during breeding season. They show a remarkable degree of mimicry so that sometimes it becomes very difficult to identify them in their habitat. In the crop-fields and gardens, these spiders are considered as one of the important biological control agent of insect pests (Barrion and Litsinger1995).

\section{Distribution}

Asia and America.

Misumenoides deccanes Tikader 1965 (Fig. 1a-f; Fig. 2) Misumenoides deccanes Tikader, Proc. Indian Acad. Sci. 61(5): 279; Tikader 1980: 152; Biswas 2009: 348. 



$1 \mathrm{~mm}$

Fig. 1. Sketch of Misumenoides deccanes Tikader: a. Whole body (dorsal view); b. Chelicerae; c. Maxillae \& Labium; d. Sternum; e. Part of hind leg; f. Epigynum. 


\section{Matertial examined}

1 female, Agricultural Diploma Institute (ADI), Faridpur, 19. IV. 1992, Coll. V. Biswas; 1 female, Shiker pur, Jhenaidah, 21. VI. 1993, Coll. Biswas; 1 female, Magura, 12. X. 1992, Coll. V. Biswas.

\section{Description of female}

Cephalothorax light brown; legs greenish and abdomen light brown. Total body length $4.20 \mathrm{~mm}$. Carapace $1.60 \mathrm{~mm}$ long, $1.70 \mathrm{~mm}$ wide; abdomen $2.60 \mathrm{~mm}$ long and $2.35 \mathrm{~mm}$ wide (Fig. 1a).



Fig. 2. Pictorial view (dorsal) of Misumenoides deccanes Tikader.

\section{Cephalothorax}

Broad, flat, little longer than wide basally; cephalic region raised, a median elevated ridge-like band distinct from the anterior margin up to the $3 / 4^{\text {th }}$ of the thoracic region; cephalic region anteriorly with a transverse tubercular ridge bearing the anterior median eyes; cervical furrows distinct; radii distinct; both anterior and posterior row of eyes recurved; lateral eyes larger, close to each other and situated on the margin of cephalic region; ocular quad wider than long. Chelicerae strong, longer than wide, only inner margin with 3 teeth, fang constricted basally (Fig. 1b). Maxillae are longer than wide, anteriorly wider and scopulate (Fig. 1c). Labium wide posteriorly, anteriorly narrowed and scopulate (Fig. 1c). Sternum elongate, wider anteriorly and pointed posteriorly, clothed with spines and hairs (Fig. 1d ). Legs long and slender; leg I very long; tibiae and metatarsi of I with strong spines ventrally (Fig. 1e); leg formula 2143 and the measurements (in $\mathrm{mm}$ ) are shown in Table 1. 
Table 1. Measurements (mm) of leg segments of Misumenoides deccanes Tikader.

\begin{tabular}{lcccccc}
\hline Leg & Femur & Patella & Tibia & Metatarsus & Tarsus & Total \\
\hline I & 2.00 & 0.80 & 1.50 & 1.50 & 0.80 & 6.60 \\
II & 2.00 & 0.80 & 1.60 & 1.50 & 0.90 & 6.80 \\
III & 1.00 & 0.30 & 0.80 & 0.40 & 0.20 & 2.70 \\
IV & 1.00 & 0.40 & 0.80 & 0.60 & 0.30 & 3.10 \\
\hline
\end{tabular}

Abdomen

Broad, longer than wide, basally broad and narrowing anteriorly, blunt posteriorly, dorsum decorated; ventrally pale with few spots; epigyne dish-like (Fig. 1e).

\section{Distribution}

Bangladesh: Faridpur, Jhenaidah, Magura; and India (Tikader 1980).

\section{ACKNOWLEDGEMENTS}

The author expresses his deep sense of gratitude to Dr. S. C. Majumder, Scientist-SD, Zoological Survey of India, Kolkata, for the identification of specimens. He is also thankful to the Principal, Government P.C. College, Bagerhat, Bangladesh for kind permission during the course of this study.

\section{REFERENCES}

Barrion, A. T. and J. A. Litsinger, 1995. Rice land spiders of South and Southeast Asia. CAB International, Wallingford, UK. 700 pp.

Biswas, V. 1995. Studies on the spider fauna (Araneae: Arachnida) of Bangladesh. Ph.D. Thesis. Department of Zoology, University of Calcutta, India. $622 \mathrm{pp}$.

Biswas, V. 2009. Arachnida. In: Ahmed (ed.). Encyclopedia of flora and fauna of Bangladesh. Vol. 18(1). Asiatic Society of Bangladesh, Dhaka, Bangladesh. 437pp.

Biswas, V. and D. Raychaudhuri. 2016. New species of the genus Camaricus Thorell, 1887 (Araneae: Thomisidae) from Bangladesh. Bangladesh J. Zool. 44(2): 255-265.

Chen, Z. F. and Z. H. Zhang. 1991. Fauna of Zhejiang, Araneida. Zhejiang Science and Technology publishing House, China. 356 pp.

Chowdhury, S. H. and S. Nagari. 1981. Rice-field spiders from Chittagong, Bangladesh. Proc. Zool. Soc. Bangladesh., pp. 53-72.

Dondale, C. D. and J. H. Redner, 1978. The Insects and arachnids of Canada part-5. The crab spiders of Canada and Alaska (Araneae: Philodromidae and Thomisidae). Agric. Can. Publ. 1663: 1-255.

Keswani, S., P. Hadole and A. Rajoria. 2012. Checklist of spiders (Arachnida: Araneae) from India. Indian J. Arachnol. 1(1): 1-129.

Keyserling, E. 1880. Die Spinnen Amerikas, I. Laterigradae, Numberg. 1: 1-283.

Kim, S. T. and Y. Lee. 2012. Invertebrate fauna of Korea (Arthropoda: Arachnida: Araneae: Thomisidae): Thomisid Spiders. Natl. Ins. Biol. Resour. 21(9): 1-88.

Lincoln, R. J. and J. G. Sheals. 1985. Invertebrate Animals Collection and Preservation. British Museum (Natural History), London, UK. 150 pp. 
Majumder, S. C. 2005. Studies on some spiders from eastern coastal region of India. Mem. Zool Surv. India. 20(3): 1-57.

Namkung, J. 2003. The Spiders of Korea. 2nd ed. Kyo-Hak Publishing Company, Korea. 648 pp.

Okuma, C., N. Q. Kamal, Y. Hirashima, Z. Alam and T. Ogata. 1993. Illustrated Monograph on the rice-field spiders of Bangladesh. IPSA-JICA, Salna, Gazipur, Bangladesh. 93 pp.

Ono, H. 1988. A revisional study of the spider family Thomisidae (Arachnida: Araneae) of Japan. Bull. Nat. Sci. Mus. Tokyo: 1-252.

Paik, K. Y. 1978. Araneae: Illustrated fauna and flora of Korea. 21: 1-546.

Pocock, R. I. 1900. The fauna of British India: Arachnida. Taylor and Francis, London, UK. 279 pp.

Schick, R. X. 1965. The crab spiders of California (Araneae: Thomisidae). Bull. Amer. Mus. Nat. Hist. 129(1): 1-180.

Sen, S., D. C. Dhali, S. Saha and D. Raychaudhuri. 2015. Spiders (Araneae: Arachnida) of reserve forests of doars: Gorumara National Park, Chapramari Wildlife Sanctuary and Mahananda Wildlife Sanctuary. World Scientific News. 20: 1-339.

Song, D. X. and M. S. Zhu. 1997. Fauna Sinica: Thomisidae. Vol. 35. Science Press, Beijing, China. $259 \mathrm{pp}$.

Song, D. X., M. S. Zhu and J. Chen. 1999. The Spiders of China. Hebei Science and Technology Publishing House, China. 640 pp.

Tikader, B. K. 1980. Fauna of India, Araneae: Thomisidae. Vol. 1(1). Zoological Survey of India, Kolkata, India. 247 pp.

Tikader, B. K. 1987. Hand book of Indian Spiders. Zoological Survey of India, Kolkata, India. 251 pp.

World Spider Catalog, 2019. World Spider Catalog, version 19.0, Natural History Museum, Bern., http://wsc.nmbe.ch (accessed on 7th April, 2019).

Yaginuma, T. 1986. Spiders of Japan in colour. 2nd ed. Hoikusha Publishing Company Ltd., Osaka, Japan. 305 pp. 